\title{
Impacts of rainfall and temperature on photoperiod insensitive sorghum cultivar : model evaluation and sensitivity analysis
}

\author{
F. M. AKINSEYE ${ }^{1,2^{*}}$, A. H. FOLORUNSHO ${ }^{2}$, AJEIGBE ${ }^{1}$, A. HAKEEM ${ }^{1}$ and S. O. AGELE ${ }^{2}$ \\ ${ }^{1}$ International Crops Research Institute for the Semi-Arid Tropics (ICRISAT-Nigeria), PMB 3491, Kano, Nagiria \\ ${ }^{2}$ Federal University and Technology, PMB 704, Akure, Ondo State, Nagiria \\ "Corresponding author: f.akinseye@cgiar.org
}

\begin{abstract}
A combination of local-scale climate and crop simulation model were used to investigate the impacts of change in temperature and rainfall on photoperiod insensitive sorghum in the Sudanian zone of Mali. In this study, the response of temperature and rainfall to yield patterns of photoperiod insensitive sorghum (Sorghum bicolor L. Moench) using the Agricultural Production Systems Simulator (APSIM) model was evaluated. Following model calibration of the cultivar at varying sowing dates over two growing seasons (2013 and 2014), a long-term simulation was run using historical weather data (1981-2010) to determine the impacts of temperature and rainfall on grain yield, total biomass and water use efficiency at varying nitrogen fertilizer applications. The results showed that model performance was excellent with the lowest mean bias error (MBE) of -2.2 days for flowering and 1.4 days for physiological maturity. Total biomass and grain yield were satisfactorily reproduced, indicating fairly low RMSE values of $21.3 \%$ for total biomass and very low RMSE of $11.2 \%$ for grain yield of the observed mean. Simulations at varying Nfertilizer application rate with increased temperature of $2{ }^{\circ} \mathrm{C}, 4^{\circ} \mathrm{C}$ and $6{ }^{\circ} \mathrm{C}$ and decreased rainfall by 25 and $50 \%(\mathrm{~W}-25 \%$ and $\mathrm{W}-50 \%)$ posed a highly significant risk to low yield compared to increase in rainfall. However, the magnitude of temperature changes showed a decline in grain yield by $10 \%$, while a decrease in rainfall by $\mathrm{W}-25 \%$ and $\mathrm{W}-50 \%$ resulted in yield decline between $5 \%$ and $37 \%$, respectively. Thus, climate-smart site-specific utilization of the photoperiod insensitive sorghum cultivar suggests more resilient and productive farming systems for sorghum in semi-arid regions of Mali.
\end{abstract}

Keywords: Crop simulation model, photoperiod insensitive, sorghum, rainfall, temperature

Among the many small grains that supply approximately $85 \%$ of the world's food energy, only three other foods (rice, wheat and maize) are consumed more than sorghum (ICRISAT, 2009). Sorghum is a dietary staple crop that contributes immensely to both domestic and commercial food needs as well as rural household income in most semiarid environment. With about 24 million hectares under cultivation, sorghum in West Africa ranked the second most important crop after maize, but average yields are low with only $800 \mathrm{kgha}^{-1}$ (Maredia et al., 2000; Akinseye, 2015). From 1979 to 2001, sorghum production in West Africa had increased from 5.1 to 13 million tonnes but regional mean yields were stagnant $\left(890 \mathrm{~kg} \mathrm{ha}^{-1}\right.$ in $1979-81,780 \mathrm{~kg} \mathrm{ha}^{-1}$ in 1992-94) (FAO, 1997). Even with the development and release of improved high yielding sorghum varieties with short growth cycles, significantly higher productivity still a mirage due to unpredictable climatic condition, low inputs applied by farmers as well as low soil fertility (Ajeigbe et al., 2018). However, rainfall and temperature remain key climatic variables to sorghum productivity. Sorghum production continues to depend mainly on traditional cultivars characterized by hardiness, photoperiod sensitivity, long stalks and low harvest index (Akinseye et al., 2017).

MacCarthy et al. (2009) reported that there is compelling evidence that climate variability and change will affect crop yields and agricultural activities as seasonal changes in rainfall and temperature could alter growing seasons, planting and harvesting calendars, water availability, increased pest, diseases and parasitic weed (striga) populations. Therefore, altering the evapotranspiration rate, photosynthesis, biomass production, and land suitability for agricultural production (Adejuwon, 2004, Mark et al., 2008, Dimes et al., 2008). Schlenker and Lobell (2010) projected a yield decrease by mid-century (2046-65) of about $20 \%$ for $\mathrm{C}_{4}$ cereals, driven by the increase in temperature. Report by Sultan et al. (2013), projected yield losses from millet and sorghum crops was induced by increase temperature leading to 
Table 1: Cultivar- specific model parameters used in sensitivity analysis simulation: sources and values

\begin{tabular}{|c|c|c|c|}
\hline Parameters & Source & Value & Units \\
\hline \multicolumn{4}{|l|}{ Thermal time accumulation } \\
\hline Duration- Emergence to end of juvenile & $\mathrm{C}$ & 205 & $\mathrm{C}$ day \\
\hline Duration- End of juvenile to panicle initiation & $\mathrm{C}$ & 201 & C day \\
\hline Duration-Flag leaf to flowering & $\mathrm{C}$ & 140 & $\mathrm{C}$ day \\
\hline Duration- flowering to start of grain filling & $\mathrm{C}$ & 80 & $\mathrm{C}$ day \\
\hline Duration- Flowering to maturity & $\mathrm{C}$ & 580 & $\mathrm{C}$ day \\
\hline Duration- maturity to seed ripening & $\mathrm{D}$ & 1 & C day \\
\hline Day length photoperiod to inhibit flowering & $\mathrm{D}$ & 12.8 & hours \\
\hline Day length photoperiod for insensitivity & $\mathrm{D}$ & 13.8 & hours \\
\hline Photoperiod slope & $\mathrm{D}$ & 11.5 & ${ }^{\circ} \mathrm{C} / \mathrm{h}$ \\
\hline Growing degrees day required to develop the most leaf ligules & $\mathrm{C}$ & 41 & ${ }^{\circ} \mathrm{C}$ day \\
\hline Growing degrees day required to develop last leaf ligules & $\mathrm{C}$ & 26.5 & C day \\
\hline Base temperature & $\mathrm{L}$ & 10 & c \\
\hline Grain growth rate & $\mathrm{C}$ & 0.00165 & $\mathrm{~g}$ \\
\hline Radiation use efficiency & $\mathrm{D}$ & 1.25 & $\mathrm{~g} / \mathrm{MJ}$ \\
\hline
\end{tabular}

L: literature; D: default value; $C$ : calibrated

increased potential evapotranspiration, crop maintenance respiration and a reduction of the crop-cycle length.

Sorghum yields were predicted to likely decrease by some $5-41 \%$ in the $21^{\text {st }}$ century over West Africa because of the expected warming, irrespective of whether rainfall increases or decreases. Current innovations with farming system models including Agricultural Production Systems sIMulator (APSIM) provides an insight which integrates knowledge of soils, site information, crops, weather and management practices to estimate crop yield and water productivity (Keating et al., 2003; Holzworth et al., 2014; Mohanty et al., 2017). It is therefore crucial to understand the uncertainty surrounding sorghum yield variability under different management practices, especially fertilizer application, considering that sorghum is one of the sustainable crops to current climate variability and future climate change. This study examined the impacts of rainfall and temperature on photoperiod insensitive sorghum cultivar relative to fertilizer applications using crop simulation model. The specific objectives are to; (i) calibrate and evaluate APSIM model to predict phenology, morphology and yields of photoperiod insensitive sorghum cultivars; (ii) model sensitivity to change in temperature and rainfall under different fertilizer application for grain yield total biomass and water use efficiency.

\section{MATERIALS AND METHODS}

\section{Experimental data for model calibration and evaluation}

The experimental data used for calibration and evaluation was conducted in 2013 and 2014 growing seasons at International Crop Research Institute for Semi-Arid Tropics (ICRISAT), Bamako, Mali (12.52 ${ }^{\circ} \mathrm{N}$ and $\left.-8.07^{\circ} \mathrm{W}\right)$. The experiment had sowing dates and varieties (10) as treatments in a randomized complete block design (RCBD) with four (4) replications. One out of ten (10) varieties tested was selected for this study which was characterized photoperiod insensitive sorghum cultivar (Cleget et al., 2009; Akinseye, 2015). The cultivar name was S621B locally called "Bambey"; a pure-line cultivar developed at ICRISAT-Mali. Sorghum was cultivated under optimum conditions which implied no water and nitrogen stress for the growth conditions during the two growing seasons. In both seasons sorghum was sown at 25 days interval which began in June with three (3) planting dates in 2013 and two (2) in 2014 cropping seasons. These planting dates covered the widest range of farmer's sowing window for sorghum in Sudan savanna zone of Mali. Plant population was 67,000 hillsha $^{-1}(0.75 \mathrm{~m}$ between rows and $0.20 \mathrm{~m}$ between hills) which was achieved by thinned to 1 plant/hill, 15 days after planting (DAP). In 2013 growing season, all the plots were fertilized using $100 \mathrm{kgha}^{-1}$ of di-ammonium phosphate at sowing and $50 \mathrm{kgha}^{-1}$ of Urea $(46 \% \mathrm{~N})$ at 40 days after 
planting. In addition to application rate used in 2013 growing season, 2014 sowing received two tonnes ( 2 tons) per hectare of manure prior to sowing incorporated during land preparation (which contain an organic matter content of $44 \%$ and $\mathrm{C}: \mathrm{N}$ ratio of 12 and organic carbon content of $22 \%$ ). Insecticides were used according to local recommendations and weeding was done manually. The detailed agronomic procedure and measurement has been reported by Akinseye (2015). Only the relevant crop parameters which include crop phenology (planting date, date of flowering and maturity), morphological traits (LAI and total leaf number per plant), grain yield and total biomass were evaluated in this study.

Long-term daily climatic records of rainfall (mm), solar radiation $\left(\mathrm{MJm}^{-2}\right)$, maximum temperature $\left({ }^{\circ} \mathrm{C}\right)$ and minimum temperature $\left({ }^{\circ} \mathrm{C}\right)$ were obtained between 1981 and 2010 from agroclimatological unit of ICRISAT-Bamako. Meanwhile, 2013 and 2014 daily records of the same weather parameters were downloaded from automatic weather station installed in less than $1 \mathrm{~km}$ radius from experimental plots were used for calibration and evaluation accordingly. Furthermore, the soil of the experimental plot sampled prior to sowing each year and characterized as a well-drained, sandy loam $(55 \%$ sand, $35 \%$ silt, and $20 \%$ clay), soil organic carbon content was low $(0.24 \%)$ and associated with this, total $\mathrm{N}$ was measured as $225 \mathrm{mgkg}^{-1}$. High available phosphorus (Bray-I) of $94.5 \mathrm{mgkg}$ ${ }^{1}$ can be traced to a long history of $\mathrm{P}$ fertilizer use on the station, with a $2.47 \mathrm{cmolkg}^{-1} \mathrm{CEC}$ and a $\mathrm{pH}$ water of 5.3. Parameters in APSIM related to water dynamics such as runoff curve number and evaporation terms were defined as Probert et al. (1998) while additional soil variables not available in the laboratory analysed data were parameterized using APSIM soil protocol reported by Dalgliesh et al. (2016).

\section{APSIM model overview, evaluation and sensitivity analysis}

The APSIM model is a modular modeling framework (Keating et al., 2003; Holzworth et al., 2014), a farming system model that simulates crop growth and development based on environmental variables. Five in-built modules namely; sorghum crop module (APSIM-sorghum), soil water module (SoilWat), soil nitrogen module (Soiln), residue module (Residue) and the manure module (Manure) were used in this study. The sorghum modules were calibrated and evaluated within the APSIM (APSIM7.9) framework for the selected sorghum cultivar. Generally, input parameterization data required by the model include crop management information, cultivar specific parameters (genetic coefficient), soil properties and daily weather records specified. Crop management and cultivar information was derived from the field experiments described above. Parameterization of drained upper limit (DUL), lower limit of plant extractable water (LL15) and saturated water content (SAT), BD, and organic carbon content (OC), initial $\mathrm{NH}_{4}-\mathrm{H}$ and $\mathrm{NO}_{3}-\mathrm{N}$ and $\mathrm{pH}$ was done using measurements obtained from the experiment and published source reported by Dalgliesh et al. (2016). Genetic coefficients are expressed in thermal degrees and photoperiod. Crop development is controlled by temperature (thermal degree days) and photoperiod. Thermal time accumulations were derived using algorithm described in Jones and Kiniry (1986) using observed phenology and weather data, a base temperature of $10^{\circ} \mathrm{C}$ and an optimal temperature of $30^{\circ} \mathrm{C}$. Potential biomass growth is a function of the intercepted radiation and the radiation-use efficiency. Water-limited growth is a function of water supply and the transpiration efficiency of the crop, which varies daily as a function of vapour pressure deficit. Actual biomass increase is simulated from either potential or water-limited growth as modified by temperature and $\mathrm{N}$ stresses.

Table 2: Model evaluations for phenological development across sowing dates

\begin{tabular}{|c|c|c|c|c|}
\hline \multirow{2}{*}{$\begin{array}{l}\text { Parameter } \\
\text { Year/sowing }\end{array}$} & \multicolumn{2}{|c|}{ Days to Flowering } & \multicolumn{2}{|c|}{ Days to physiological Maturity } \\
\hline & Observed & Simulated & Observed & Simulated \\
\hline 2013_SD_1 & 69 & 71 & 98 & 103 \\
\hline 2013_SD_2 & 71 & 70 & 97 & 102 \\
\hline 2013_SD_3 & 74 & 72 & 98 & 104 \\
\hline 2014_SD_1 & 82 & 76 & 110 & 104 \\
\hline 2014_SD_2 & 80 & 76 & 108 & 104 \\
\hline Mean & 75 & 73 & 102 & 103.4 \\
\hline RMSE (days) & & 3.5 & & 5.3 \\
\hline MBE (days) & & -2.2 & & 1.4 \\
\hline
\end{tabular}



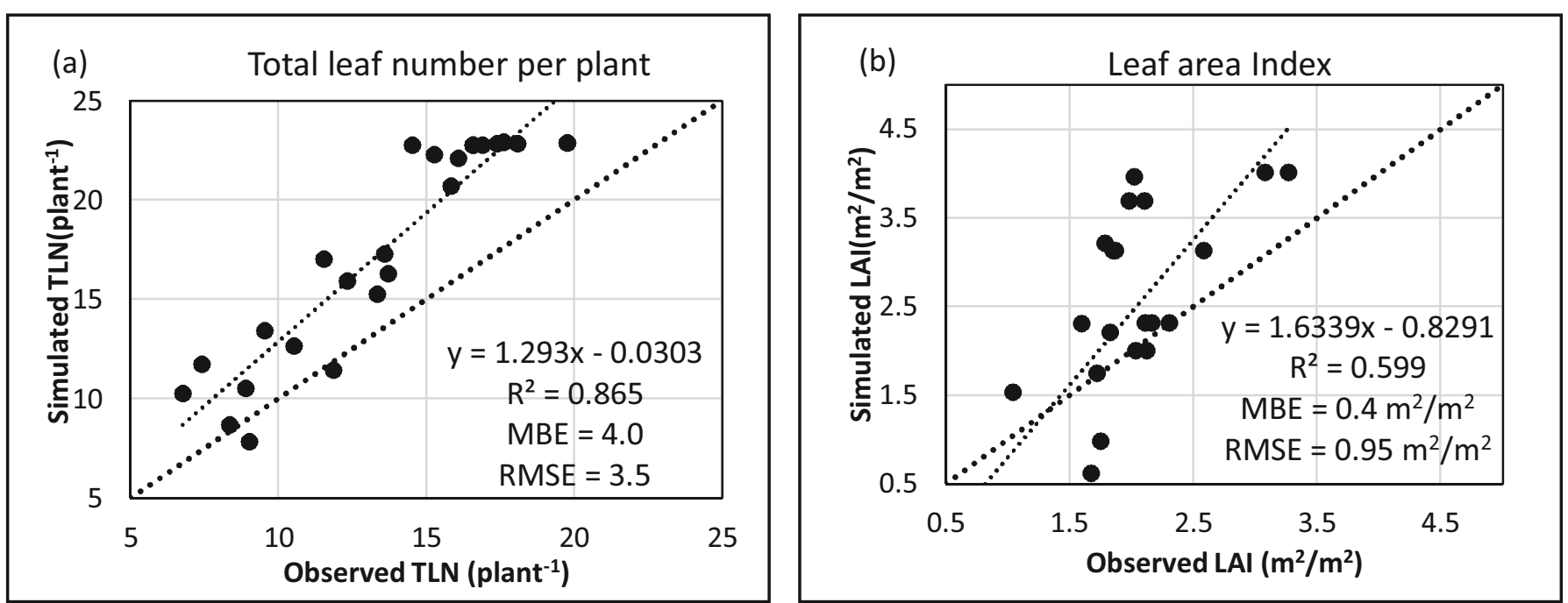

Fig.1: Comparison between model-simulated and observed values for (a) total leaf number (TLN) and (b) leaf area index (LAI) across sowing dates
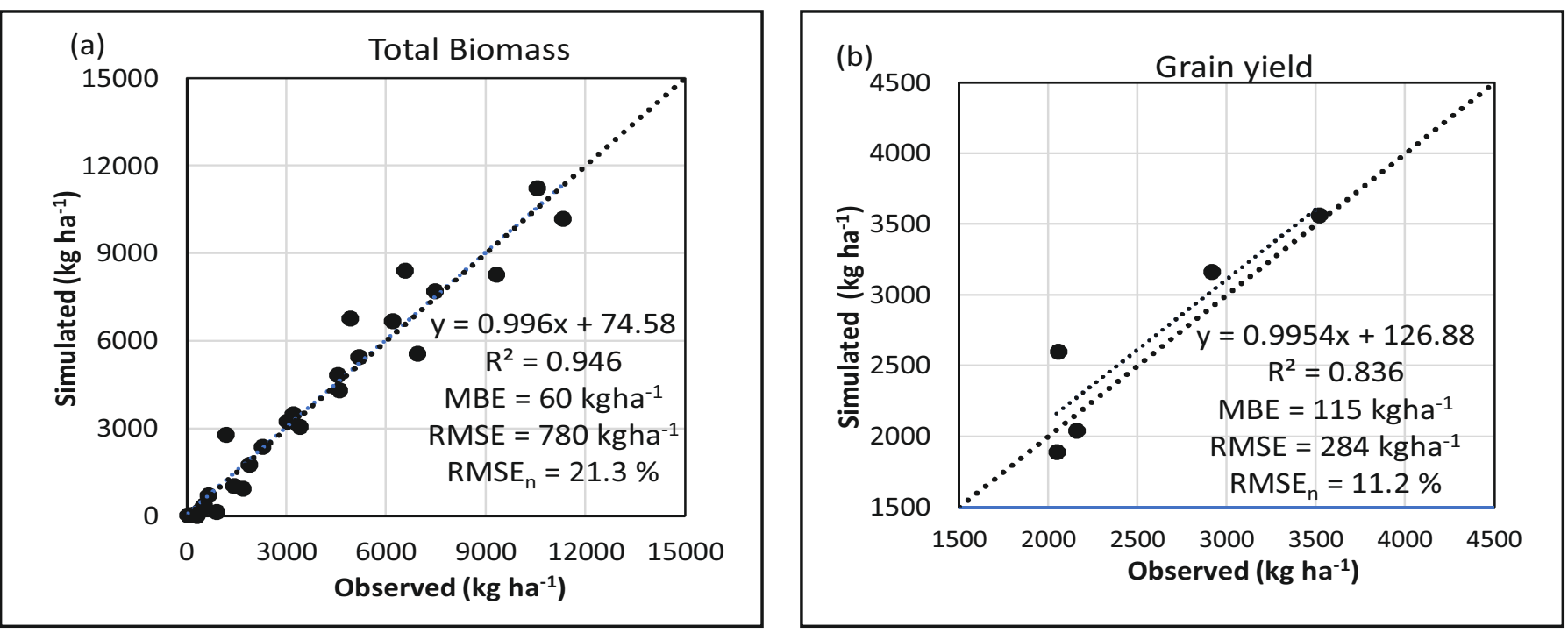

Fig.2: Comparison between model-simulated and observed values for (a) total biomass and (b) final grain yield across sowing dates
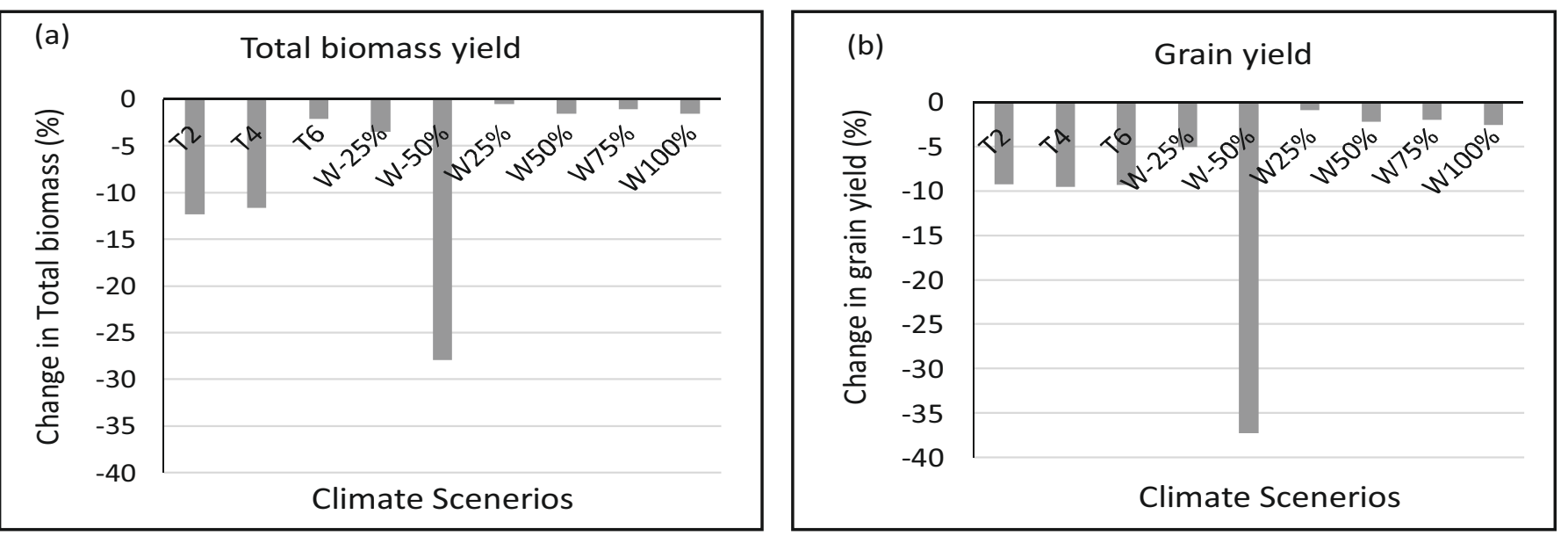

Fig. 3: Mean percentage change for simulated grain yield and total biomass across $\mathrm{N}$-fertilizer rates based on the current climatic condition (1980-2010) 
Table 3: Mean simulated grain yield, total biomass and grain yield water use efficiency (GY_WUE) between 1981 and 2010 based on increase temperatures (minimum and maximum) and rainfall changes at varying fertilizer applications for a photoperiod insensitive sorghum cultivar

\begin{tabular}{|c|c|c|c|c|c|c|c|c|c|c|}
\hline N-input & $\begin{array}{l}\text { Baseline } \\
\text { climate }\end{array}$ & $\mathrm{T} 2$ & $\mathrm{~T} 4$ & T6 & $\mathrm{W}-25 \%$ & $\mathrm{~W}-50 \%$ & $\mathrm{~W} 25 \%$ & W50\% & $\mathrm{W} 75 \%$ & $\mathrm{~W} 100 \%$ \\
\hline & \multicolumn{10}{|c|}{ Grain yield $\left(\mathrm{kgha}^{-1}\right)$} \\
\hline 0 & 2258 & 2181 & 2168 & 2136 & 2283 & 1631 & 2166 & 2110 & 2082 & 2048 \\
\hline 40 & 2733 & 2435 & 2429 & 2449 & 2548 & 1636 & 2721 & 2691 & 2698 & 2682 \\
\hline 80 & 2752 & 2441 & 2435 & 2458 & 2552 & 1636 & 2764 & 2744 & 2767 & 2765 \\
\hline 120 & 2754 & 2444 & 2438 & 2460 & 2554 & 1637 & 2766 & 2747 & 2770 & 2769 \\
\hline $\operatorname{LSD}(0.05)$ & $136^{* *}$ & & & & & & & & & \\
\hline \multirow[t]{2}{*}{ CV of year(\%) } & 11.2 & & & & & & & & & \\
\hline & \multicolumn{10}{|c|}{ Total Dry matter $\left(\mathrm{kg} \mathrm{ha}^{-1}\right)$} \\
\hline 0 & 7696 & 7058 & 7108 & 7798 & 7794 & 6138 & 7470 & 7331 & 7277 & 7177 \\
\hline 40 & 8884 & 7686 & 7748 & 8610 & 8456 & 6203 & 8867 & 8785 & 8839 & 8796 \\
\hline 80 & 8932 & 7702 & 7766 & 8636 & 8468 & 6207 & 8977 & 8921 & 9013 & 9004 \\
\hline 120 & 8941 & 7711 & 7775 & 8644 & 8475 & 6211 & 8986 & 8930 & 9023 & 9013 \\
\hline $\operatorname{LSD}(0.05)$ & $379 * *$ & & & & & & & & & \\
\hline \multirow[t]{2}{*}{ CV of year(\%) } & 14.6 & & & & & & & & & \\
\hline & \multicolumn{10}{|c|}{ Grain yield water use efficiency $\left(\mathrm{kg} \mathrm{ha}^{-1} \mathrm{~mm}^{-1}\right)$} \\
\hline 0 & 6.2 & 5.8 & 5.4 & 4.8 & 6.4 & 5.3 & 6 & 5.9 & 5.9 & 5.8 \\
\hline 40 & 7.1 & 6.2 & 5.8 & 5.2 & 6.8 & 5.3 & 7.1 & 7.0 & 7.1 & 7.1 \\
\hline 80 & 7.1 & 6.3 & 5.8 & 5.2 & 6.8 & 5.3 & 7.1 & 7.1 & 7.2 & 7.2 \\
\hline 120 & 7.1 & 6.3 & 5.8 & 5.3 & 6.8 & 5.3 & 7.1 & 7.1 & 7.2 & 7.2 \\
\hline $\operatorname{LSD}(0.05)$ & $0.30 * *$ & & & & & & & & & \\
\hline CV of year(\%) & 12.2 & & & & & & & & & \\
\hline
\end{tabular}

NB: BC-Baseline Climate, T2 - 6 means increase temperature (minimum and maximum) by T2, T4 and T6 respectively; $W$-25\% \& $-50 \%$ indicates rainfall decline by $25 \%$ \& $50 \%$; W25-100\% indicated increase rainfall by $25-100 \%$

Based on the phenological data collected, the cultivargenetic coefficients were calibrated until there was appreciable agreement between simulated and observed values for phenology and yield data. The experiments were run with each set of genetic coefficients (associated with each in a planting date) and the simulated and observed values were used to compute the root mean square error (RMSE). RMSE is defined as;

$R M S E=\frac{\sqrt{\sum_{i=1}^{n}\left(S_{i}-O_{i}\right)^{2}}}{n}$

Where: $\mathrm{S}_{\mathrm{i}}$ represents the simulated, $\mathrm{O}_{\mathrm{i}}$ represents the observed value, $\mathrm{n}$ represents the number of iteration taken into consideration.

The normalized root mean square error $\left(\mathrm{RMSE}_{\mathrm{n}}\right)$ expressed in percent gives a measure $(\%)$ of the relative difference of simulated versus observed data.

$R M S E_{n}=\frac{\sqrt{\sum_{i=1}^{n}\left(S_{i}-O_{i}\right)^{2}}}{n} X \frac{100}{M}$.

Mean bias error (MBE) measures the average magnitude of the errors in a set of predictions to whether overestimated and underestimated by the model.

$M B E=\frac{\sum_{i=1}^{n}(S i-O i)}{n}$

Furthermore, sensitivity analysis was conducted to evaluate Sorghum yield response to changes in key meteorological variables (Temperature and Rainfall) at current concentrations of $\mathrm{CO}_{2}$ of $380 \mathrm{ppm}$. The simulation analyses considered a long-term climatic record as a baseline climate (1981-2010) using different $\mathrm{N}$-fertilizer application rate for grain yield, total biomass and grain yield water use efficiency (GY_WUE). The simulations were carried out at 
varying minimum and maximum temperatures for $2^{\circ} \mathrm{C}(\mathrm{T} 2)$, $4^{\circ} \mathrm{C}$ (T4) and $6^{\circ} \mathrm{C}$ (T6). Also, decrease in daily rainfall at $25 \%$ (W-25\%), and 50\% (W-50\%), increase in daily rainfall at 25\% (W25\%), 50\% (W50\%), 75\% (W75\%), 100\% (W100\%), respectively.

\section{RESULTS AND DISCUSSION}

\section{Model parameterization and evaluation}

The cultivar-calibrated and model default parameters are presented in Table 1. Meanwhile, model evaluation for phenology, morphology and yield parameters are presented in Table 2 and Fig. $1 \& 2$ respectively. Table 1 shows that the cultivar-specific parameters were well calibrated accounted for the high-yielding characteristics of the photoperiod insensitive sorghum tested. Table 2 indicates excellent agreement between model-simulated and mean observed values for phonological parameters with high accuracy indicated mean bias error (MBE) of 2.2 days for flowering and 1.4 days for physiological maturity of the mean observed value. The results further showed that the model overestimated both total leaf number (TLN) and leaf area Index (LAI) as compared to the mean observed values (Fig. 1). The overestimation could be attributed to model inability to capture the early growth stage of the crop similar to earlier reported by Akinseye et al., (2017) However, there was a good agreement between model simulated and observed values for total biomass and grain yield across the sowing dates (Fig. 2). Model performance shows that MBE estimated $60 \mathrm{~kg} \mathrm{ha}^{-1}$ for total biomass and $115 \mathrm{~kg} \mathrm{ha}^{-1}$ for grain yield and RMSE $(780 \mathrm{~kg}$ $\mathrm{ha}^{-1}$ ) for total biomass and $284 \mathrm{~kg} \mathrm{ha}^{-1}$ for grain yield values. Also, the results indicate strong coefficient of determination $\left(\mathrm{R}^{2}\right)$ between the simulated and observed values. Since they compared the agreement of simulated versus observed values, thus the lower the values, the better the model in explaining most of the variations in the dataset.

\section{Impacts of temperature and rainfall on sorghum yield at varying $N$-fertilizer applications}

Table 3 displayed the response of the grain yield, total biomass and grain yield water use efficiency (GY_WUE) to climate scenarios (temperature and rainfall changes) and also different $\mathrm{N}$-fertilizer rates as inputs. These climate scenarios include minimum and maximum temperatures increase of 2 ${ }^{\circ} \mathrm{C}, 4{ }^{\circ} \mathrm{C}$ and $6{ }^{\circ} \mathrm{C}(\mathrm{T} 2, \mathrm{~T} 4$ and T6), rainfall decrease of $25 \%$ and $50 \%$, and increase of $25 \%, 50 \%, 75 \%$ and $100 \%$. The grain yield, total biomass, and GY_WUE increased significantly with increased $\mathrm{N}$-fertilizer rate; however, there were no significant differences between 40 and 120 under different climate scenarios considered plus baseline climate. Across the fertilizer rate, simulated grain yield and total biomass reduced by a mean of $260 \mathrm{~kg} \mathrm{ha}^{-1}$ and $1000 \mathrm{~kg} \mathrm{ha}^{-1}$ with exception of T6 for total biomass when compared baseline climate and increased temperature T2 - T6. Similarly, the mean GY_WUE significantly decrease with increase temperature from T2 - T6 across the N-fertilizer rate, which implies that the amount of grain produced by the amount of water use reduces with increase temperature. Also, the mean simulated grain yield reduced by $140 \mathrm{~kg} \mathrm{ha}^{-1}$ and $990 \mathrm{~kg} \mathrm{ha}^{-1}$ at seasonal rainfall decline of $25 \%(\mathrm{~W}-25 \%)$ and $50 \%$ (W-50\%), while the magnitude of grain yield loss by increase rainfall (W25\% $\mathrm{W} 100 \%$ ) was significantly low ranged from 20 to $60 \mathrm{~kg} \mathrm{ha}$ ${ }^{1}$ across $\mathrm{N}$ - fertilizer rate. Additionally, the water use efficiency (WUE) decreased respectively by $4.2 \%$ and $25.4 \%$ with a regress in daily rainfall by $25 \%(\mathrm{~W}-25 \%)$ and $50 \%(\mathrm{~W}-50 \%)$. Conversely, water use efficiency remained relatively same with an increase in rainfall from $25 \%$ to $100 \%$, and a corresponding rise in the fertilizer usage. Thus, the nine climate scenarios considered indicate a significant negative impact on the grain yield and total biomass at varying magnitude (Fig.3). The results show that grain yield would reduce by closely $10 \%$ with temperature increase and $37 \%$ yield loss in more drier condition when rainfall amount is reduced by $50 \%(\mathrm{~W}-50 \%)$. Total biomass indicates a yield loss of $28 \%$ for a very pronounced reduction in soil moisture content as a result of rainfall decrease of $50 \%$ while temperature increase of $\mathrm{T} 2$ and $\mathrm{T} 4$ would also give rise to a drop in total biomass by $12 \%$ except for T6. The increase in temperature produces a corresponding rise in the evapotranspiration rate, leading to more loss of the water use efficiency. These results are comparable to findings reported by Schlenker and Lobell (2010) projected the effect of temperature and rainfall on sorghum crop. As shown in a report also by Sultan et al. (2013), projected yield losses from sorghum crops was induced by increase temperature leading to increased potential evapotranspiration, crop maintenance respiration and a reduction of the crop-cycle length. This study however justifies through simulations that rainfall increase plays a little but important role in affecting the sorghum grain yield, water use efficiency and total biomass. The major factors responsible for grain yield loss at harvest are decrease in rainfall amount and increase in temperature as predicted above.

\section{CONCLUSION}

Understanding the crop response towards changing climate is an essential step in formulating adaptation strategies 
and policy. In this study, we evaluated APSIM model for simulating the phenological and morphological traits as well as grain yield and total biomass of photoperiod insensitive sorghum cultivar planted across sowing dates. The sensitivity analysis of photoperiod insensitive sorghum to climate variables (temperature and rainfall) varied from year to year and is largely dependent on water availability. The sorghum yield is more sensitive to increase in temperature and declined rainfall. The ability to replicate phenological characterization after subsequent calibration and evaluation provide a platform whereby various simulations could be performed with the aim of increasing sorghum productivity. The study therefore, concluded that APSIM model provides a sound scientific anticipation into sorghum yield variations and can serve as an input to policy and decision making for climate change adaptation.

\section{ACKNOWLEDGEMENT}

The authors would like to thank the International Crop Research Institute for Semi-Arid Tropics (ICRISAT), Nigeria for providing institutional support for the study. The experiment was conducted under the former $\mathrm{CG}$ research Program-West and Central Africa for Dryland Cereal.

\section{REFERENCES}

Adejuwon, S.A. (2004). Impact of climate variability and climate change on crop yield in Nigeria. Contributed Paper to Stakeholders Workshop on Assessment of Impact and Adaptation to Climate Change (AIACC): 2-8.

Ajeigbe, H.A., Akinseye, F.M., Kunihya, A. and Jonah, J. (2018). Productivity and Water Use Efficiency of Sorghum [Sorghum bicolor (L.) Moench] Grown Under Different Nitrogen Applications in Sudan Savanna Zone, Nigeria. Hindawi Int. J. Agron., https://doi.org/10.1155/2018/7676058

Akinseye, F.M. (2015). Factoring climate variability and change into crop models for enhancing Sorghum performance in the West African Semi-Arid Tropics (Ph.D. Thesis), http://www.wascal.org/publications/ doctoral-theses.

Akinseye, F.M., Adam, M., Hoffmann, M.P., Traore, P.C.S., Agele, S.O. and Whitbread, A.M. (2017). Assessing crop model improvements through comparison of sorghum (Sorghum bicolor L. moench) simulation models: a case study for West African cultivars. Field
Crop Res. 201:19-31, http://dx.doi.org/10.1016/ j.fcr.2016.10.015.

Clerget, B., Dingkuhn, M., Gozé, E., Rattunde, H.F.W. and Ney, B. (2009). Variability of phyllochron, plastochron and rate of increase in height in photoperiod-sensitive sorghum varieties. Ann. Bot., 101: 579-594.

Dalgliesh, N., Hochman, Z., Huth, N. and Holzworth, D. (2016). A Protocol for the Development of APSOIL Parameter values for the Use in APSIM Version 4. CSIRO, Australia.

Dimes, J., Cooper, P. and Rao, K.P.C. (2008). Climate Change Impact on Crop Productivity in the Semi-Arid Tropics of Zimbabwe in the 21st Century. Proceedings of the Workshop on Increasing the Productivity and Sustainability of Rain-Fed Cropping Systems of Poor Smallholder Farmers, Tamale, 22-25 September 2008, 189-198.

FAO. (1997). The global economy of sorghum and millet: Facts, trends and prospects. FAO (Rome, Italy) and ICRISAT, Patancheru, India, p.68.

Holzworth, D.P., Huth, N.I., deVoil, P.G., Zurcher, E.J., Herrmann, N.I., McLean, G. et al. (2014) APSIM Evolution towards a new generation of agricultural systems simulation. Environ. Model. Softw. 62, 327350 .

Jones, C.A. and Kiniry, J.R. (1986). CERES-Maize: A Simulation Model of Maize Growth and Development. College Station, TX: Texas A\&M University Press.

Keating, B.A., Carberry, P.S., Hammer, G.L., Probert, M.E., Robertson, M.J., D Holzworth, Huth, N.I, Hargreaves, J.N.G., Meinke, H., Hochman, Z., Verburg, K., Snow, V., Dimes, J.P., Silburn, M., Wang, W., Brown, S., Bristow, K.L., Asseng, S., Chapman, S., McCown, R.L., Freebairn, D.M. and Smith, C.J. (2003). An Overview of APSIM: A Model Designed for Farming Systems Simulation. Eur. J. Agron., 18: 267-288

MacCarthy, D.S., Sommer, R. and Vlek, P.L.G. (2009). Modeling the impacts of contrasting nutrient and residue management practices on grain yield of sorghum (Sorghum bicolor (L.) Moench) in a semi-arid region of Ghana using APSIM. Field Crop. Res. 113(2): 105-115

Maredia, M., Byerlee, D. and Pee, P. (1998). Impacts of food crop improvement research in Africa. SPAAR 
Occasional Papers Series No. 1, Washington, D.C., 34p. (Web: http: //www.worldbank.org).

Maredia, M.K., Byerlee, D. and Pee, P. (2000). Impacts of food crop improvement research: Evidence from sub Saharan Africa. Food Policy, 25: 531-559.

Mark, R.C., Mandy, E., Gary, Y., Lan, B., Saleemul, H. and Rowena, V.S. (2008). Climate Change and Agriculture; threats and opportunities. Federal Ministry for Economic Cooperation and Development Germany.

Mohanty, M., Sinha, N.K., Sonali, P., Mcdermid, Chaudhary, R.S., Sammireddy, K., Hati, K.M., Somasundaram, J., Lenka, S., Patidar, R.K., Prabhakar, M., SrinivasRao Ch., Patra, A.K. (2017). Climate change impacts vis-avis productivity of soybean in vertisol of Madhya Pradesh, J. Agrometeorol., 19(1): 10-16.
Probert, M.E., Dimes, J.P., Keating, B.A., Dalal, R.C. and Strong, W.M. (1998). APSIM's water and nitrogen modules and simulation of the dynamics of water and nitrogen in fallow systems. Agric. Syst. 56: 1-28.

Schlenker, W. and Lobell, D.B. (2010). Robust negative impacts of climate change on African agriculture. Environ. Res. Lett., 5:014010, http://dx.doi:10.1088/ 1748-9326/5/1/014010.

Sultan, B., Roudier, P., Quirion, P., Alhassane, A., Muller, B., Dingkuhn, M., Ciais, P., Guimberteau, M., Traoreand, S. and Baron, C. (2013). Assessing climate change impacts on sorghum and millet yields in the Sudanian and Sahelian savannas of West Africa. Environ. Res. Lett., 8:014040, http://dx.doi:10.1088/ 17489326/8/1/014040. 